\title{
Proton Modified Pt Zeolite Fuel Cell Electrocatalysts
}

\author{
Jun $\mathrm{Yao}^{1^{*}}$, Yufeng $\mathrm{Yao}^{2}$ and Hossein Mirzaii ${ }^{3}$ \\ 1-School of Engineering, University of Lincoln, Brayford Pool, Lincoln LN6 7TS, UK \\ jyao@lincoln.ac.uk
}

2-Faculty of Environment and Technology, Department of Engineering Design and Mathematics, University of the West of England, Coldharbour Lane, Bristol BS16 1QY, UK

yufeng.yao@uwe.ac.uk

3-Faculty of Science, Engineering and Computing, Kingston University, Roehampton Vale, Friars Avenue, London SW15 3DW, UK

\section{Abstract}

H.Mirzaii@kingston.ac.uk

$\mathrm{NaY}$ Zeolite has been selected as a suitable material to host $1.5 \mathrm{wt} \%$ Platinum $(\mathrm{Pt})$ loading on zeolite using ion exchange methods of $\mathrm{Pt}\left(\mathrm{NH}_{3}\right)_{4}\left(\mathrm{NO}_{3}\right)_{2}$ without excess $\mathrm{NH}_{4} \mathrm{NO}_{3}$ nitrate and $\mathrm{Pt}\left(\mathrm{NH}_{3}\right)_{4}\left(\mathrm{NO}_{3}\right)_{2}$ with excess $\mathrm{NH}_{4} \mathrm{NO}_{3}$ nitrate. The structure/reactivity relationship of $\mathrm{Pt}$ nanoparticle was experimentally studied via Nafion@ ${ }^{@}$ bound electrodes to investigate the interaction nature of Pt with zeolite and electron transfer. By using extended X-ray adsorption fine structure technique, Pt particle size was predicted as $0.7-1.5 \mathrm{~nm}$. It was found Pt oxides can be electrochemically reduced via a hydrogen 'spillover' phenomenon. A highly dispersed small Pt particle distribution can be achieved with excessive $\mathrm{H}^{+}$ions on zeolite acidic sites.

Keywords: Pt/Y zeolite electrocatalyst, Nanoparticle, CV, EXAFS, Fuel cell

\section{Introduction}

Pt is an important catalyst of polymer electrolyte membrane fuel cell (PEMFC), because of its ultra-high catalytic properties that can largely promote high energy density. Unfortunately $\mathrm{Pt}$ is an extremely expensive metal material and its performance degrades very rapidly, that will hinder its wider applications in fuel cell. Hence, the creation of high Pt active surface with less metal content is one of important but challenging themes in fuel cell electro-catalyst research.

The use of carbon nanotube or zeolite to facilitate the adsorption of small catalyst particles was used as a solution for particle cluster size control problem [1]. The excessive hydrogen ion exchanged zeolite has rich protons at zeolite acidic center to form hydroxyl groups with oxygen, leading to the interaction of metal precursors with zeolite and thus decrease the sintering propensity of the metal [2]. Nevertheless, the surface oxygen groups, which form the anchoring sites of metallic precursors and metals, are well-known in determining the catalyst supporting material properties [3]. Koningsberger et al. [4] has investigated the influence of oxygen atom charge transfer on zeolite using the extended X-Ray adsorption Fine Structure (EXAFS). The increasing of electronegativity nearby the support oxygen atoms was found to increase zeolite alkalinity. The interaction between Pt and oxygen would move Pt electrons more nearer to oxygen. A charge transfer can be subsequently occurred from or to Pt metal particles. This has particularly accounted for the PtHY zeolite catalyst, as $\mathrm{H}^{+}$ions exchanged into zeolite structure can result in a significant increase of the $\mathrm{O}, \mathrm{Si}$ and $\mathrm{Al}$ binding energy.

A highly dispersed $\mathrm{Pt} /$ zeolite catalyst using $\mathrm{O}_{2}$ calcination and $\mathrm{H}_{2}$ reduction process was reported by Sachtler and Gallezot [5]. Pt was found favourable to locate in supercages at 300 ${ }^{\circ} \mathrm{C}$ with a particle size of $6-13 \AA$. The XPS study has detected Pt particle migration through zeolite supercages to sodalite cages at calcination temperature of $450{ }^{\circ} \mathrm{C}$ [6]. Pt constrained within zeolite supercages were varied from single atom to a particle in an order of $1-2 \mathrm{~nm}$ [7], forming a cluster of 10 to 25 atoms [8]. The Pt-Pt binding energy was found to increase with Pt electron deficiency. An average of approximately 20 to 30 atoms with $11.3 \AA$ per particle was predicted at a reduction temperature of $300^{\circ} \mathrm{C}$ and was increased to $16 \AA$ at 500 ${ }^{\circ} \mathrm{C}$ in $\mathrm{H}_{2}$ [9]. Yokoyama et al. [10] also revealed that the Pt-Pt bonding distance of Pt cluster encaged in zeolite supercages was shorter than the bulk Pt metal. This suggested that the charge transfer from Pt clusters to the substrate was stronger in the $\mathrm{Pt} / \mathrm{Y}$ zeolite catalyst. The 
contraction of Pt-Pt bond distance on zeolite was mainly due to the increase of Pt-Pt bonding energy caused by electron deficiency.

Although zeolite is a well-known dc insulator [11], its capability as a solution-like ionic conduction linkage commonly used within electrochemical environment indicates that the electrochemical reaction on Al-Si zeolite is able to occur in a charge-balanced ionic environment [12]. The Pt metal particles are able to be completely hydrated and dehydrated due to a great capacity of water absorption on zeolite [12]. The role of high water content in electrochemical reaction is considered to facilitate the spillover of hydrogen [13]. In fact the water can act as a 'vehicle' to transport ions through zeolite free volume space by hitching a ride on water. This phenomenon is called 'spillover' [14], mainly involving hydrogen and oxygen-containing species and has been observed on catalyst such as $\mathrm{Pt} / \mathrm{C}$ [15], $\mathrm{Pt} / \mathrm{SiO}_{2}$ [16], $\mathrm{Pt} / \mathrm{Al}_{2} \mathrm{O}_{3}$ [17] and $\mathrm{Pt} /$ zeolite [18] in gas phase. Therefore, it is important to investigate $\mathrm{H}^{+}$ spillover effect in zeolite - supported Pt $\mid$ Nafion ${ }^{\circledR}$ bound Pt zeolite electrode system [7].

This study contributes to the understanding of electron transfer at the interface between $\mathrm{Pt} /$ zeolite electrode and the solution, and the Pt particle size associated electro-catalytic efficiency in electrochemical reaction. The structure of the Pt particle will be investigated using the extended X-Ray Adsorption Fine Structure (EXAFS) and the correspondent Pt electrocatalytic performance will be determined via cyclic voltammetry $(\mathrm{CV})$ measurement.

\section{Experimental}

The $1.5 \mathrm{wt} \% \mathrm{Pt}$ loading was made by ion exchange of $\mathrm{Pt}^{2+}$ ions with $\mathrm{Na}^{+}$on $\mathrm{Y}$ zeolite using either $\operatorname{Pt}\left(\mathrm{NH}_{3}\right)_{4}\left(\mathrm{NO}_{3}\right)_{2}$ or $\mathrm{Pt}\left(\mathrm{NH}_{3}\right)_{4}\left(\mathrm{NO}_{3}\right)_{2} / \mathrm{NH}_{4} \mathrm{NO}_{3}$ solution. The ion exchange procedure was followed by methods developed by Boyan [8] and Lalchan [19] at natural condition. The Pt microstructure synthesis was then followed the procedure developed by Gallezot and coworkers [6]. The samples were calcined at $350{ }^{\circ} \mathrm{C}$ in $\mathrm{O}_{2}$ and later reduced in $\mathrm{H}_{2}$ at $400{ }^{\circ} \mathrm{C}$.

The Nafion ${ }^{@}$ bound electrode was made by spreading a thin paste of $1.5 \mathrm{wt} \% \mathrm{Pt} / \mathrm{Y}$ zeolite or $\mathrm{Pt} / \mathrm{HY}$ zeolite and carbon powder (untreated XC-72R carbon powder) mixture with Nafion@ solution ( $5 \mathrm{wt} \%$ solution in lower alcohols from Aldrich) to carbon paper (E-TEK TGHP-90). A disc of $2.5 \mathrm{~cm}^{2}$ diameter of electrode was cut for cyclic voltammetry measurement and 1.3 $\mathrm{cm}^{2}$ diameter for EXAFS study via $\mathrm{Hg} / \mathrm{Hg}_{2} \mathrm{SO}_{4}$ Mercury/Mercurous Sulfate (MMS) reference electrode. The electrolyte was put in 2.5 and $1 \mathrm{~mol} \mathrm{~cm}^{-3}$ sulphuric acid $\left(\mathrm{H}_{2} \mathrm{SO}_{4}\right)$ solutions for Laboratory cyclic voltammetry and in-situ EXAFS measurements respectively, using a computer-controlled potentiostat (Auto-Lab PGSTAT20) at a constant scan rate (dE/dt) of 1 $\mathrm{mV} / \mathrm{s}$ [20]. The oxidation/reduction of the electro-active species of interest was detected between $-0.65 \mathrm{~V}$ and $0.5 \mathrm{~V}$, in which no any decomposition occurred [21]. The extended X-ray absorption fine structure (EXAFS) measurements were performed using the Synchrotron Radiation Source (SRS) at Daresbury Laboratory, UK. The wiggler beam line was operated at $2 \mathrm{GeV}$ and $100 \mathrm{~mA}$. The high-order harmonics were removed using a double-crystal Si220 monochromator. The Pt $\mathrm{L}_{\| 1}$ absorption edge was located by $50 \%$ detuning of a harmonic beam with a Pt foil used as a reference sample for EXAFS data collection.

\section{Results and Discussion}

\subsection{Zeolite BET surface areas measurement}

Zeolite crystalline structure was characterised by Brunauer-Emmett-Teller (BET) surface area measurement. Figure 1 depicts the zeolite BET surface area measurements for electrocatalysts, such as (a) $1.5 \mathrm{wt} \% \mathrm{Pt}$ loading on zeolite calcined at $350{ }^{\circ} \mathrm{C}$ and reduced at $400{ }^{\circ} \mathrm{C}$ (i.e. 15PtANCR4) and (b) $1.5 \mathrm{wt} \%$ Pt loading on zeolite made with excess $\mathrm{NH}_{4} \mathrm{NO}_{4}$ ion exchange calcined at $350^{\circ} \mathrm{C}$ and $400{ }^{\circ} \mathrm{C}$ (i.e. 15PtANXCR4), respectively. The plain zeolite and carbon XC-72R powders are used as references and their surface areas were measured at $632 \mathrm{~m}^{2} \mathrm{~g}^{-1}$ and $200 \mathrm{~m}^{2} \mathrm{~g}^{-1}$ (see Table 1). The discrepancy of sample 15PtANXCR4 zeolite surface area is very small compared to that of plain zeolite. A well preserved zeolite crystalline structure was determined for sample 15PtANXCR4 made by excess $\mathrm{NH}_{4} \mathrm{NO}_{4}$ ion exchange method. The Pt zeolite electrocatalyst with no excess $\mathrm{NH}_{4} \mathrm{NO}_{4}$ ion change (i.e.15PtANCR4) has shown a significant reduction of zeolite surface area which was measured at $168 \mathrm{~m}^{2} \mathrm{~g}^{-1}$, indicating the blockage of zeolite opening pores in a small channel. 

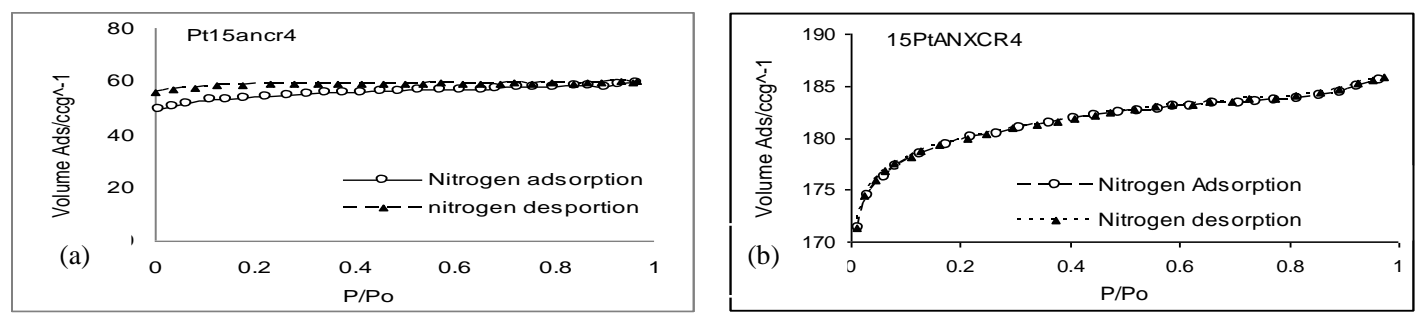

Figure1. Volumetric uptake of nitrogen at 77 Kelvin with absorption in open dotted line, and desorption in filled dotted line. (a) Sample15PtANCR4; (b) Sample 15PtANXCR4.

Table 1. BET surface area measurement for plain zeolite, untreated carbon XC-72R, $1.5 \mathrm{wt} \%$ $\mathrm{Pt} /$ Yzeolite(i.e.15PtANCR4) and 1.5 wt\% Pt/HY zeolite (i.e.15PtANXCR4) electrocatalysts.

\begin{tabular}{|c|c|c|c|c|}
\hline Acronym Name & Plain Zeolite Catalyst & Carbon XC-72R & 15PtANCR4 & 15PtANXCR4 \\
\hline Surface Area $\mathrm{m}^{2} / \mathrm{g}$ & $623.2 \pm 0.1 \%$ & $200 \pm 0.1 \%$ & $168 \pm 0.1 \%$ & $539 \pm 1.0 \%$ \\
\hline
\end{tabular}

\subsection{The cyclic voltammetry (CV) measurement}

The cyclic voltammetry (CV) measurement was performed in an electrochemical cell to determine the electro-activity of species using Nafion ${ }^{\circledR}$ bound electrode made by a mixture of $\mathrm{Pt} /$ zeolite electrocatalyst and carbon powder. The response of electrochemical reaction was determined by monitoring current change via potential. The CV measurement of $1.5 \mathrm{wt} \% \mathrm{Pt}$ loading on Pt/Y zeolite carbon | Nafion ${ }^{\circledR}$ electrodes (i.e. 15PtANCR4 and 15PtANXCR4) and $1.5 \mathrm{wt} \% \mathrm{Pt} / \mathrm{C} \mid$ Nafion ${ }^{\circledR}$ electrode (i.e. 15Pt/XC-72R) made from a commercially available 40 $w t \% \mathrm{Pt} / \mathrm{XC}-72 \mathrm{R}$ carbon catalyst mixed with the extra XC-72R carbon is depicted in Figure 2 to investigate hydrogen adsorption/desorption activity on Pt at $-0.65 \mathrm{~V}$ in $2.5 \mathrm{~mol} \mathrm{dm}^{-3} \mathrm{H}_{2} \mathrm{SO}_{4}$ solution. Figure $2 \mathrm{a}$ depicts the $\mathrm{CV}$ of $1.5 \mathrm{wt} \% \mathrm{Pt} / \mathrm{CX}-72 \mathrm{R}$ electrode consisting of three distinguished regions, a hydrogen adsorption/desorption region (peak $A$ ) starting at potential region of $-0.32 \mathrm{~V}$ to $-0.65 \mathrm{~V}$; i.e. oxide region and the double layer region. The peak $\mathrm{B}$ is responsible for a hydrogen evolution and the peak $\mathrm{C}$ is linked with the weakly adsorbed $\mathrm{H}^{+}$ ions forming covalent bond on Pt. The $\mathrm{H}$ re-oxidation (peak $\mathrm{D}$ ) is observed on the hydrogen re-oxidation (HRO) region of $-0.65 \mathrm{~V}$ to $-0.36 \mathrm{~V}$ and the peak $\mathrm{E}$ is associated with weakly bound $\mathrm{H}$ desorption. The current increase between $0.12 \mathrm{~V}$ and $0.5 \mathrm{~V}$ indicates the formation of $\mathrm{Pt}$ oxide species correspondent to an oxide stripping region of $0.5 \mathrm{~V}$ to $0.02 \mathrm{~V}$. A charge separation is determined in a double layer region from $0.02 \mathrm{~V}$ to $-0.36 \mathrm{~V}$ and $-0.36 \mathrm{~V}$ to $0.12 \mathrm{~V}$ in a reverse sweep manner. Figure $2 b$ shows a consistent electrochemical oxidation/reduction features for sample 15PtANCR4 and 15PtANXCR4. A strong hydrogen adsorption peak has been observed at $-0.6 \mathrm{~V}$ and $-0.56 \mathrm{~V}$ for both electrodes. No weakly bound hydrogen adsorption peak can be determined, as both weakly and strongly bound hydrogen may adsorb similar amount of energy, resulting in difficulties to distinguish them unless a much slow sweep rate less than $1 \mathrm{mV} / \mathrm{s}$ used. A hydrogen desorption peak was detected at $-0.56 \mathrm{~V}$, followed by hydrogen evolution at $-0.65 \mathrm{~V}$. The large hydrogen coverage is observed for 15PtANXCR4. The electrochemical responses coincide to previous findings reported by Konigsberg and his co-workers [22]. The excess $\mathrm{NH}_{4} \mathrm{NO}_{3}$ on zeolite can also result in small but well dispersed Pt clusters inside the zeolite cage.
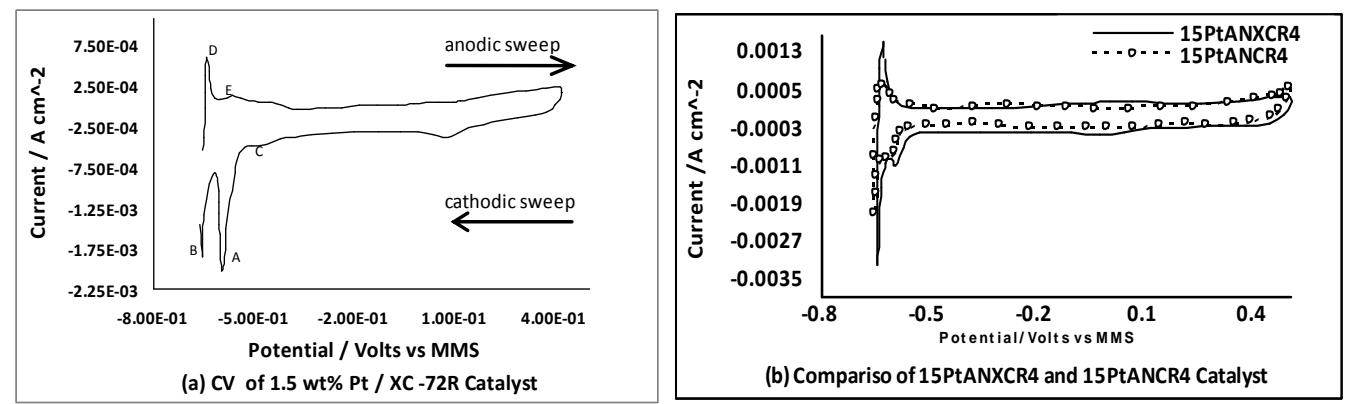

Figure 2. Steady state CV curves are measured at a scan rate of $1 \mathrm{mV} / \mathrm{s}$ in $2.5 \mathrm{~mol} \mathrm{dm}^{-3}$ $\mathrm{H}_{2} \mathrm{SO}_{4}$ solution. (a) Sample 15Pt/XC-72R, (b) comparison of CV for samples 15PtANCR4 and 15 PtANXCR4. 
The presence of electron/ion transfer at the interface of Nafion ${ }^{@}$ bound Pt/zeolite electrode and electrolyte solution can be demonstrated by CV method. Gallezot et al. [22, 23] predicted Pt particles more likely remained in zeolite supercage at a reduction temperature of $400{ }^{\circ} \mathrm{C}$, where electrochemical species were easy to access on zeolite Pt active site. Zeolite is a type of dc electronic insulator material that cannot be used as direct electrode materials. However, zeolite is capable of solution-like ionic conduction which can act as an electron bank to contribute electrons to or garner electron from a reactant [24]. This commonly links with electrochemical environment for reaction to occur in a charge-balanced ionic environment.

The hydrogen 'spillover' pathway on Pt/C catalyst was investigated by Srinivas and Rao [25]. They found the adsorption/desorption can occur on carbon based Pt active sites. Later study by McBreen [26] has further revealed the current generation on Pt active sites, remotely from conducting material surface with fast surface mobility of adsorbed species on the electrode. Therefore, the surface active sites of Pt particles that are not in direct contact with solid conductive polymer electrolytes might be also involved in an interfacial process through the pathway of surface conductance. Two possible pathways either the surface mobility of adsorbed species or hydrogen adatoms $/ \mathrm{H}^{+}$ion may spill over through zeolite framework or on electrode surface [13] in which hydrogen ions $\left(\mathrm{H}^{+}\right)$were able to form $\mathrm{OH}$ group with carbon/zeolite acidic surface oxides. The hydrogen spillover on $\mathrm{Pt}$ and zeolite acidic sites has also been studied in gas phase [18], in which an anti-bonding state of Pt-H interaction relating to the electronic properties of the catalytic active sites has been observed [4]. This finding can also be used to explain the hydrogen spillover between Pt electrode and solution in electrochemical environment. In addition, $\mathrm{H}^{+}$spillover may occur during the surface diffusion process of the absorbed species [18]. Water is an important spice to facilitate hydrogen migrating between zeolite and Pt. The electron transfer may take place between electrode and solution via free species, such as $\mathrm{H}^{+}$and $\mathrm{H}_{3} \mathrm{O}^{+}$. lons are transported through free species by hitching a ride on water during their migration through zeolite channels and between the interface of electrodes and solution.

\subsection{In-situ EXAFS study for $1.5 \mathrm{wt} \% \mathrm{Pt} / \mathrm{Y}$ zeolite electrocatalysts}

Figure 3 illustrates the EXAFS data fitting for electrocatalysts 15PtANCR4 (with no excess nitrate ion exchange) and 15PtANXCR4 (with excess nitrate ion exchange). The correspondent fitting results are presented in Table 2. The in-situ EXAFS data is collected at Pt $\mathrm{L}_{\text {III }}$ edge at room temperature and potential of $-0.65 \mathrm{~V}$ in $1.0 \mathrm{~mol} \mathrm{dm}^{-3} \mathrm{H}_{2} \mathrm{SO}_{4}$ solution. For electro-catalyst 15PtANCR4, the curve fitting (in dotted lines) matches the general form of the raw data (in dashed lines) very well and the data fitting is extended up to 3 shells with shell 1 and shell 2 predicted for Pt and shell 3 for oxygen, respectively. The Pt coordination numbers in shell 1 and shell 2 are approximately 7.45 and 2.05. The introducing of third Pt-O shell has a significant improvement of data fitting quality. The first shell Pt cluster is predicted with Pt-Pt distance of $2.77 \AA$, implicating the preserving of the bulk Pt characteristics. The Pt-O bond may attribute to the direct link of Pt associated with oxygen on zeolite Lewis acidic site. The increase of Pt electron deficiency associated to either zeolite acidity or the decrease of Pt-Pt bonding energy is leading to a slight increase of Pt-Pt bond (2.77 $\AA$ ), compared to the standard metallic Pt bond of $2.75 \AA$. The curve fitting for 15PtANXCR4 is extended up to 2 shells. The Pt atom is fully reduced as no oxygen atom is predicted at neighbouring Pt shells. The total Pt atoms are fitted up to two shells at 7.86, indicating the Pt particle size is small to excess nitrate salt ion exchanged electrocatalyst 15PtANXCR4, compared to sample with no excessive $\mathrm{H}^{+}$presence (i.e. 15PtANCR4) with an average of 9.50 atoms. The Pt particle size is estimated at $1.5 \mathrm{~nm}$ and $0.8 \mathrm{~nm}$ for two samples 15PtANCR4 and 15PtANXCR4, respectively.

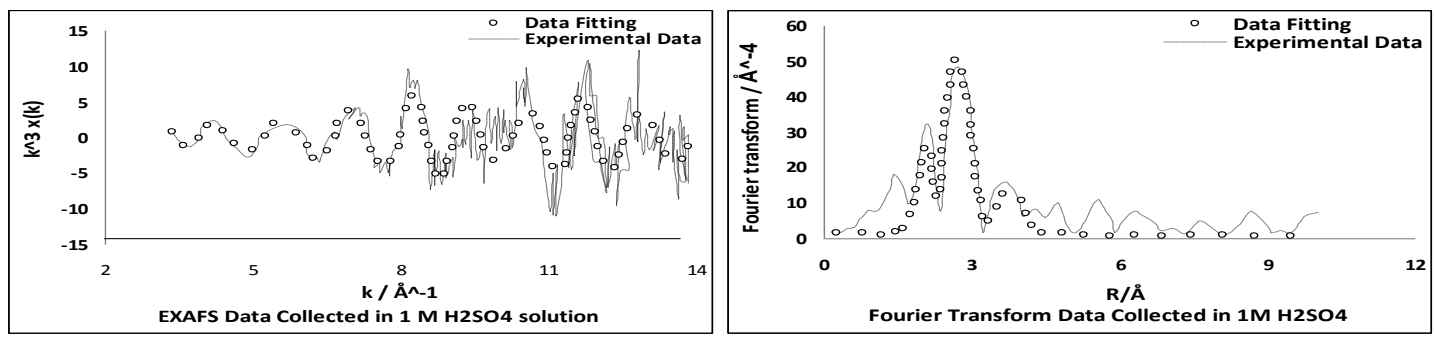

(a) 15PtANCR4, test data and Fourier transformation graph 

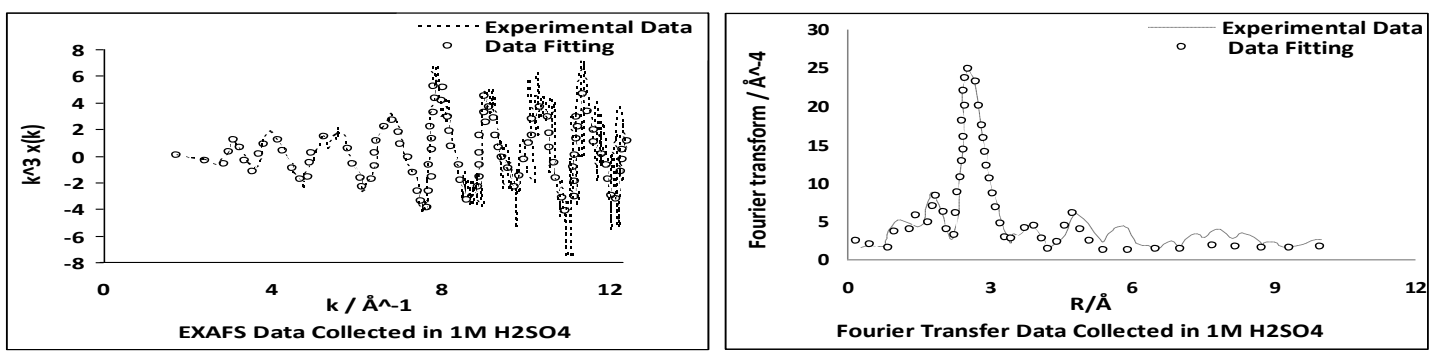

(b) 15PtANXCR4, test data and Fourier transformation graph

Figure 3. The in-situ EXAFS data fitting for $1.5 \mathrm{wt} \% \mathrm{Pt} \mathrm{Y}$ zeolite catalysts with phase correction. The experimental data and the fitting results are presented in dashed line and dotted line, respectively. Data is collected at $-0.65 \mathrm{~V}$ vs MMS reference electrode in $1.0 \mathrm{~mol}$ $\mathrm{dm}^{-3} \mathrm{H}_{2} \mathrm{SO}_{4}$ solution under potential deposition. The EXAFS data was collected at $P t L_{\text {III }}$ edge at room temperature. (a) Electro-catalyst 15PtANCR4, (b) Electro-catalyst 15PtANXCR4.

Table 2. The data fitting results for $1.5 \mathrm{wt} \% \mathrm{Pt} / \mathrm{Y}$ Zeolite for electrocatalysts $15 \mathrm{PtANCR} 4$ and 15PtANXCR4 at $-0.65 \mathrm{~V}$ potential in $1.0 \mathrm{~mol} \mathrm{dm}^{-3} \mathrm{H}_{2} \mathrm{SO}_{4}$ solution.

\begin{tabular}{|l|c|c|c|c|}
\hline 15PtANCR4 & Atom coordination & Shell 1 - Pt & Shell 2 - Pt & Shell 3 - O \\
\cline { 2 - 5 } & $\mathrm{N}$ & 7.45 & 2.05 & 0.75 \\
\cline { 2 - 5 } & $\mathrm{R}(\AA)$ & 2.77 & 3.85 & 2.19 \\
\hline 15PtANXCR4 & $\mathrm{N}$ & 6.38 & 1.48 & no \\
\cline { 2 - 5 } & $\mathrm{R}(\AA)$ & 2.77 & 3.90 & No \\
\hline
\end{tabular}

\subsection{Pt active surface area measurement and Pt distribution on zeolite}

The Pt active surface area under hydrogen peak is measured at $103.57 \mathrm{~m}^{2} / \mathrm{g}$ for 15PtANXCR4 and $51.29 \mathrm{~m}^{2} / \mathrm{g}$ for 15PtANCR4, correspondent to $0.77 \mathrm{wt} \%$ and $1.52 \mathrm{wt} \% \mathrm{Pt}$ loading on zeolite as seen in Table 3 and Figure 4, respectively. The results are consistent to $\mathrm{Pt}$ surface atom distributions. The total $\mathrm{Pt}$ atoms per $\mathrm{cm}^{2}$ correspondent to $\mathrm{Pt}$ loading for sample 15PtANXCR4 have shown $50 \%$ reduction, compared to sample 15PtANCR4. The Pt surface atom dispersion is $29.44 \%$ and $14.66 \%$ for two catalyst samples 15 PtANXCR4 and 15PtANCR4, respectively.

Table 3. Pt active surface area $\mathrm{m}^{2}$ per gram

\begin{tabular}{|l|c|c|c|c|}
\hline Sample & 15PtANCR4 & 15PtANXCR4 & 15Pt/XC-72R & Dispersion $\mathrm{N}_{\mathrm{S}} / \mathrm{N}_{\mathrm{T}}(\%)$ \\
\hline $\begin{array}{c}\mathrm{Pt} \text { active surface area } \\
\text { under } \mathrm{H} \text { Area } / \mathrm{m}^{2} / \mathrm{g}\end{array}$ & 51.29 & 103.57 & 0.133 & 14.66 \\
\hline $\mathrm{wt} \% \mathrm{Pt}$ & 1.52 & 0.77 & 1.49 & 29.44 \\
\hline
\end{tabular}

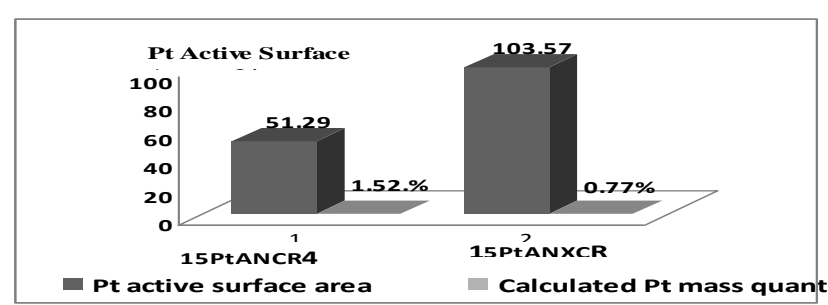

Figure 4. Comparison of Pt active surface area distributions of two test samples.

The present study has shown that a highly dispersed Pt particle distribution on zeolite can be achieved with the presence of excessive $\mathrm{H}^{+}$ions on zeolite. The zeolite acidity may affect $\mathrm{Pt}$ catalytic activity, as the formation of metal - proton could adduct results in Pt electron change and hydrogen spillover phenomenon. The spillover $\mathrm{H}^{+}$ions can also be transmitted at the surfaces of the zeolite support to increase the surface conductivity of the support [27]. 


\section{Conclusion}

This study has contributed to the understanding of electron transfer between zeolite and $\mathrm{Pt}$ metal particle. The relations of Pt electro-catalytic efficiency correspondent to Pt particle size, $\mathrm{Pt}$ distribution and electron transfer pathway have been investigated by electrochemical control and the extended X-Ray adsorption fine structure (EXAFS). The cyclic voltammogram feature of hydrogen oxidation/reduction peak for Nafion ${ }^{\circledR}$ electrode made with excess or no excess nitrate $\left(\mathrm{NH}_{4} \mathrm{NH}_{3}\right)$ ion exchange (i.e. 15PtANXCR4 or 15PtANCR4) is found consistent to that of $1.5 \mathrm{wt} \% \mathrm{Pt} / \mathrm{XC}-72 \mathrm{R}$. The electrochemically active surface area (EASA) measurement indicates significantly high Pt distributions for catalyst 15PtANXCR4 than that of catalyst 15PtANCR4. The presence of excess $\mathrm{H}^{+}$can facilitate electrochemical reaction on $\mathrm{Pt}$ active sites and $\mathrm{H}^{+}$is also able to improve metal-proton adduct formation and increase electrode surface conductivity by spillover $\mathrm{H}^{+}$on zeolite. Water is important for hydrogen migration via free species, such as $\mathrm{H}^{+}$and $\mathrm{H}_{3} \mathrm{O}^{+}$, by hitching a ride on water. The Pt particle cluster is predicted at $0.8 \mathrm{~nm}$ for catalyst 15PtANXCR4 and $1.5 \mathrm{~nm}$ for catalyst 15PtANCR4, correspondent to Pt distributions of $29.44 \%$ and $14.66 \%$ with Pt loading of $0.77 \mathrm{wt} \%$ and $1.54 \mathrm{wt} \%$, respectively. Conclusively, the $1.5 \mathrm{wt} \% \mathrm{Pt}$ loading on zeolite made by excess nitrate (i.e. 15PtANXCR4) has shown a great advantage to provide high surface area with efficient mass transport capacity for electro-active species to and from electrode surface in comparison of that without excess nitrate ion exchanged electro-catalysts (i.e.15PtANCR4).

\section{References}

1. H.N. Yang, J.Y. Lee, Y. Na, S.C. Yi, and W.J. Kim, Microporous and Mesoporous Materials, 2012, 152:148-156.

2. F. Rodriguez-Reinoso, The role of carbon materials in heterogeneous catalysis, 1998, 36:159-75.

3. E. Auer, A. Freund, J. Pietsch, and T. Tacke, Appl Catal A, 1998,173:259-71.

4. D.C. Koningsberger, J de Graaf, B.L. Mojet, D.E. Ramaker, and J.T. Miller, Applied Catalysis A, 2000, 191:205-220.

5. W.M.H. Sachtler and Z. Zhang, Advances in Catalysis, 1993, 39:129-220.

6. P. Gallezot, A. Alarcon-Diaz, J.A. Dalmon, A.J. Renouprez, and B. Imeuk, J. of Catalysis, 1975, 39:334-349.

7. D.R. Rolison, E.A. Heys, and W.E. Rudzinski, J. of Physical Chemistry, 1989, 93:5524-31.

8. B.I. Boyanov and T.I. Morriso, J. of Physical Chemistry, 1996, 100:16310-16317.

9. K.I. Pandya, S.M. Heald, J.A. Hriljac, L.Petrakis, and J. Fraissard, J. of Physical Chemistry, 1996, 100:5070-5077.

10. T. Yakoyama, N., Kosugi, K. Asakura, Y. Iwasawa and H. Kuroda, Journal De Physique Colloques, 1986, 47:C8-273 - C8-276.

11. D.W. Breck, Zeolite Molecular Sieves: Structure, Chemistry and Use, 1974, WileyInterscience, New York.

12. D.R. Rolison, J. of Chemical Review, 1990, 90(5):867-878.

13. W.J. Liu, B. L. Wu, and C.S. Cha, J. of Electroanalytical Chemistry, 1999, 476:101-108.

14. P.A. Sermon and G.C. Bond, Catal. Rev. 1973, 8: 211-240.

15. V.S. Bagotzky, L.S. Kanevsky, and V.S. Palanker, Electrochim. Acta 1973, 18:473-518.

16. J.F.C. Candau and W.C. Conner, J. of Catalysis, 1987, 106:378-385.

17. R.R. Cavanagh and J.T. Yates Jr., J. of Catalysis, 1981, 68: 22-26.

18. A. Zhang, I. Nakamura, and K. Fujimoto, J. of Catalysis, 1997, 168(2):328-333.

19. L. Persaud, A.J. Bard, A. Campion, M.A. Fox, T.E. Mallouk, S.E. Webber, and J.M. White, Inorg. Chem., 1987, 26(22):3825-3827.

20. H. Gerischer and C.W. Tobias, Advances in Electrochemsitry and Electrochemical

Engineering, Vol 11, 1978, John Willey \& Sons.

21. C. Brett and A.M.O. Brett, Electroanalysis, 1998, Oxford University Press.

22. Z. Zhang, T.T. Wong, and W.M.H. Sachtler, J. of Catalysis, 1991, 128(1):13-22.

23. P. Gallezot, Catal. Rev. Sci. Eng., 1979, 20(1):121-154.

24. G. Larsen and G.L. Haller, Catalysis Letters, 1989, 3:103-110.

25. S. Srinivas and P. Rao, J. of Catalysis, 1994, 148(2):470-477.

26. J. McBreen, J. Electrochem. Soc. 1985, 132(5):1112-1116.

27. J.M. Herrmann, J. of Catalysis, 1984, 89(2):404-412. 